\title{
A pilot study to assess short-term physiologic outcomes of transitioning infants with severe bronchopulmonary dysplasia from ICU to two subacute ventilators
}

\author{
Robert M. DiBlasi, RRT-NPS, FAARC ${ }^{1,2}$, Dave N. Crotwell, RRT-NPS, FAARC ${ }^{2}$, Jonathan Poli ${ }^{1}$, Justin Hotz, RRT-NPS ${ }^{3}$, \\ Jonathan D. Cogen $\mathrm{MD}^{4}$, Edward Carter, $\mathrm{MD}^{5}$
}

\begin{abstract}
RM DiBlasi, DN Crotwell, J Poli, J Hotz, JD Cogen, E Carter. A pilot study to assess short-term physiologic outcomes of transitioning infants with severe bronchopulmonary dysplasia from ICU to two subacute ventilators. Can J Respir Ther 2018;54(1):1-6. doi: 10.29390/ cjrt-2018-001.

Introduction: This study was designed to evaluate short-term physiologic outcomes of transitioning neonates with bronchopulmonary dysplasia (BPD) from intensive care unit (ICU) ventilators to both the Trilogy 202 (Philips Healthcare, Andover, MA) and LTV 1200 (CareFusion, Yorba Linda, CA) subacute ventilators.

Methods: Six infants with BPD requiring tracheostomies for support with a neonatal-specific ICU ventilator underwent placement of esophageal balloon catheters, airway pressure transducers, flow sensors, oxygen saturation $\left(\mathrm{SpO}_{2}\right)$, and end tidal carbon dioxide $\left(\mathrm{P}_{\mathrm{ET}} \mathrm{CO}_{2}\right)$ monitors. Noninvasive gas exchange, airflow, and airway and esophageal pressures $\left(\mathrm{P}_{E S}\right)$ were recorded following $20 \mathrm{~min}$ on the ICU ventilator. The infants were placed on the Trilogy 202 and LTV 1200 ventilators in random order at identical settings as the ICU ventilator. We measured noninvasive gas exchange, pressure-rate product (respiratory rate $\times \Delta \mathrm{P}_{E S}$ ), ventilator response times, and the percentage of spontaneous breaths that triggered the ventilator at 20 min in each subject while being supported with each of the different subacute ventilators.

Results: The mean (SD) weight of the six infants was $4.983(0.56) \mathrm{kg}$. There were no differences in heart rate $(p=0.51)$ or $\mathrm{SpO}_{2}(p=0.97)$ but lower $\mathrm{P}_{\mathrm{ET}} \mathrm{CO}_{2}, \Delta \mathrm{P}_{\mathrm{ES}}$, respiratory rate, pressure rate-product, response times, and greater percentage of subject initiated breaths that triggered the ventilator $(p<0.05)$ was observed with the Trilogy 202 than the LTV 1200. All six infants transitioned successfully from the ICU ventilator to the Trilogy 202 ventilator.

Conclusion: In this small group of infants with BPD, the Trilogy 202 ventilator performed better than the LTV 1200. The improved subject efforts, per cent subject triggering, and response times observed with the Trilogy are likely related to differences in triggering algorithms, location of triggering mechanisms, and gas delivery system performance within the ventilators. These pilot data may be useful for informing future clinical study design and understanding differences in the level of support provided by different subacute ventilators in infants with BPD.
\end{abstract}

Key Words: chronic lung disease; bronchopulmonary dysplasia; infant mechanical ventilation; subacute ventilation; weaning; patient-ventilator synchrony

\section{INTRODUCTION}

Chronic lung disease of prematurity/bronchopulmonary dysplasia (BPD) is a serious complication in premature infants, which can lead to tracheostomy tube placement and prolonged ventilation beyond the neonatal intensive care unit (NICU) setting. The prevalence of long-term mechanical ventilation with BPD outside of the NICU is not well delineated, but some sources indicate that the need has steadily increased over the last two decades [1-4]. Cristea et al. [5] reported nearly a four-fold rise between 1984 and 2010 (1.23 vs 4.77 per 100,000 live births, respectively). A likely cause of prolonged intensive care unit (ICU) stay following tracheotomy in ventilator dependent infants may be related to the difficulty in transitioning from ICU ventilators to subacute/homecare ventilators. Potential reasons for failure to convert from an ICU ventilator to a subacute one may include the inability to trigger the ventilator, less rapid response times, increased dead space in subacute ventilator tubing, and bias flow differences between ICU and subacute ventilators. Sensitive breath-detection during mechanical ventilation has been associated with shorter response times and fewer ineffective triggering efforts [6]. Infants that experience dysynchrony due to poor trigger response with subacute ventilators may require sedation, higher ventilator settings, or the need to be placed back onto the ICU ventilator until they are large enough to successfully trigger mechanical breaths and have a slower respiratory rate.

In the past 10 years, recent advances in subacute ventilator technology have resulted in a proliferation of new microprocessor-controlled subacute/homecare ventilators. These ventilators are small, lightweight, and portable. They use batteries that are capable of lasting several hours, and most incorporate an internal air compressor or turbine-based flow generator. While many of these devices are approved for pediatric subjects weighing $5 \mathrm{~kg}$ or more, it is unclear whether they are capable of responding to the specific needs of smaller infants or those that have weak or ineffective inspiratory efforts or significant lung disease. Ventilators that provide more effective respiratory support and comfort during spontaneous breathing may facilitate the conversion the from an ICU ventilator to a subacute one.

The Trilogy 202 (Philips Respironics, Murraysville, PA) and the LTV 1200 (Carefusion, Yorba Linda, CA) are widely used home ventilators. We evaluated how these ventilators performed in a clinical setting in

${ }^{1}$ Center for Developmental Therapeutics, Seattle Children's Research Institute, Seattle, WA, USA

${ }^{2}$ Respiratory Care Department, Seattle Children's Hospital, Seattle, WA, USA

${ }^{3}$ Respiratory Care Department, Children's Hospital of Los Angeles, Los Angeles, CA, USA

${ }^{4}$ Division of Pulmonary and Sleep Medicine, Department of Pediatrics, University of Washington and Seattle Children's Hospital, Seattle, WA, USA

${ }^{5}$ Division of Pulmonary and Sleep Medicine, Banner Health, Phoenix, AZ, USA

Correspondence: Robert M. DiBlasi, Seattle Children's Research Institute, 1900 Ninth Ave, Seattle, WA 98101, USA. E-mail: robert.diblasi@seattlechildrens.org 
infants with BPD that required long-term ventilator support via tracheostomy tubes. We hypothesized there would be no differences in noninvasive gas exchange, indices of work of breathing, and triggering between these two ventilators.

\section{METHODS}

Subjects

The Seattle Children's Hospital Institutional Review Board (IRB) reviewed/approved the study on 15 May 2013 and deemed this work to be a quality improvement initiative. Routine esophageal pressure $\left(\mathrm{P}_{\mathrm{ES}}\right)$ monitoring and transitioning from ICU ventilators to subacute ventilators are both considered standard clinical practice for any patient requiring chronic ventilation at Seattle Children's Hospital ICUs. As such, we were not required by the IRB to obtain informed consent.

Clinically stable infants with severe BPD with cuffed tracheostomy tubes in place for ongoing mechanical ventilation residing in the NICU and ready to transition to a subacute ventilator were eligible for the study. They also needed to be cleared by the clinical team for trials before transitioning to the subacute ventilator. Severe BPD was defined as: FIO $\geq 0.30$ or continuous positive airway pressure or mechanical ventilation required at 36 postmenstrual week for infants born at $<32$ weeks [7]. Exclusion criteria were: the ongoing need for moderate-deep sedation that resulted in no spontaneous breathing efforts, receiving neuromuscular blocking agents, and (or) a recent history of apnea, central hypoventilation syndrome, or neuromuscular disease. All infants were supported initially with either the AVEA (Carefusion, Yorba Linda, CA) or the Draeger VN 500 (Draeger Medical, Lubeck, Germany) ICU ventilator. These ventilators incorporate proximal hot-wire anemometers to allow sensitive flow triggering between the patient $\mathrm{Y}$ and airway opening.

\section{Subacute ventilators}

The LTV 1200 is a microprocessor-controlled, turbine-based flow ventilator that uses a pediatric dual-limb circuit and a pneumatically controlled positive end expired pressure (PEEP)/exhalation valve. A differential pressure pneumotachometer integrated into a modified Y connector of the subject circuit allows triggering and enables flow, volume, and pressure measurements proximal to the subject's airway. The minimum flow trigger setting on the LTV 1200 is $1 \mathrm{~L} / \mathrm{min}$ and the preset bias flow is $10 \mathrm{~L} / \mathrm{min}$. The LTV 1200 has leak compensation that will gradually adjust the sensitivity up to maximum subject leak of $6 \mathrm{~L} / \mathrm{min}$.

The Trilogy 202, like the LTV 1200, is a turbine-based flow ventilator. It incorporates a pediatric single-limb (passive) circuit with an integrated fixed orifice exhalation valve. Subject triggering and flow and pressure measurements are sensed at the ventilator with an internal mass flow anemometer. Similar to the LTV 1200, the Trilogy 202 minimum flow trigger is $1 \mathrm{~L} / \mathrm{min}$, and the bias flow varies based on subject leak, wherein:Bias Flow $=7 \times \mathrm{PEEP}^{0.6}$. For example, a subject receiving $6 \mathrm{cmH}_{2} \mathrm{O}$ of PEEP who has no tracheostomy leak may have a bias flow of approximately $10.6 \mathrm{~L} / \mathrm{min}$, but this value could be higher with greater PEEP or when a leak is present or both. However, during exhalation, the Trilogy 202 turbine will reduce flow to keep PEEP constant.

The Trilogy 202 ventilator also has the option to use a dual-limb (active) circuit with a differential pressure pneumotachometer that has an approximate dead space $\sim 7 \mathrm{~mL}$. When the Active Flow circuit is chosen, the machine measures flow from a proximal flow element. This flow is used to estimate volume, to trigger, and in some cases cycle breath delivery. Prior to the clinical trial, we evaluated several subacute ventilators using a spontaneously breathing lung model configured with lung mechanics similar to those observed in infants with BPD (unpublished data). We found that with the Trilogy 202, ventilator performance did not differ between the active dual limb circuit (with proximal flow sensor) and passive single-limb circuit configurations. Thus, we chose to forego the active circuit and only use the passive circuit with the Trilogy 202 for our study.

Heated and humidified gases were provided with a Fisher and Paykel MR 840 humidifier (Auckland, NZ), and each of the ventilator circuits were connected to the tracheostomy tubes using a Pediatric Omni-Flex Connector (Carefusion, Yorba Linda, CA).

\section{Monitoring devices}

Infants were monitored with esophageal balloon catheters, airway pressure $\left(\mathrm{P}_{\mathrm{AW}}\right)$ transducers, flow pneumotachometer, oxygen saturation $\left(\mathrm{SpO}_{2}\right.$ ) monitor ( $\mathrm{Rad} 7$, Massimo Corporation, Irvine, CA), and end tidal carbon dioxide $\left(\mathrm{P}_{\mathrm{ET}} \mathrm{CO}_{2}\right)$ monitors (Microstream; Oridion, Needham, MA) while receiving mechanical ventilation. A single lumen air-filled, balloon-tipped 6 French $\mathrm{P}_{\mathrm{ES}}$ catheter (Cardinal Healthcare, Dublin, $\mathrm{OH}$ ) was positioned in the lower esophagus and the balloon was inflated with $0.2 \mathrm{~mL}$ of air. Placement of the $\mathrm{P}_{\mathrm{ES}}$ catheter enables direct measurement of $\mathrm{P}_{\mathrm{ES}}$, which is an estimate of pleural pressure. We confirmed appropriate placement of the catheter using the occlusion technique [8]. Pre-existing nasogastric feeding tubes were not removed for this study. The $\mathrm{P}_{\mathrm{AW}}$ and $\mathrm{P}_{\mathrm{ES}}$ were obtained using calibrated micromachined piezo resistive silicon pressure transducers (XRA515GN, Honeywell, Morristown, NJ, range $0-1054.5 \mathrm{cmH}_{2} \mathrm{O}$ ). The differential pressure p7neumotachometer (4500A, Hans Rudolph, Kansas City, MO) was placed in series between the subject and the tracheostomy tube to measure flow. Outputs from the $\mathrm{P}_{\mathrm{AW}}, \mathrm{P}_{\mathrm{ES}}$, and pneumotachometer were sampled at $1024 \mathrm{~Hz}$, using a 16-bit analog/digital (A/D) converter (DT9804-EC-I-BNC, Data Translation, Marlboro, MA) and were processed using a fourth-order Butterworth low-pass filter with a cut-off frequency of $20 \mathrm{~Hz}$.

\section{Study protocol and primary measures}

Each infant served as their own control and were supported initially with an ICU ventilator and then consecutively with each of the different subacute ventilators on the same day as part of a crossover design. Before transitioning to the subacute ventilators the mandatory ICU ventilator rates were adjusted (over $10 \mathrm{~min}$ ) so that all subjects were breathing spontaneously in order to evaluate subject-ventilator interaction and triggering. The order for which each of the subacute ventilators was first initiated was varied on each of the different days of testing. They were placed on identical settings as the ICU ventilator for 20 min with each of the two subacute ventilators and then returned to the ICU ventilator for a $20 \mathrm{~min}$ "washout" period between testing with each subacute ventilator. In each case the pressure control SIMV with pressure support mode was used. Once infants were placed on a subacute ventilator, the slope (rise) of the inspiratory flow was adjusted independently so that peak inspiratory pressure (PIP) measured on the subacute ventilators was similar to those measured at the airway with the ICU ventilator. In addition, we adjusted flow trigger settings to maintain the lowest value that did not result in auto-cycling of the ventilator (as confirmed by real time $\mathrm{P}_{\mathrm{ES}}$ waveform analysis).

It was determined a priori that any infant who did not tolerate a subacute ventilator based on $\mathrm{SpO}_{2}<85 \%$ on the same $\mathrm{FIO}$, used with the ICU ventilator, and (or) significantly increased work of breathing, and (or) $\mathrm{P}_{\mathrm{FT}} \mathrm{CO}_{2}$ increase $>20 \%$ from the value when on the ICU ventilator would be placed back on the ICU ventilator and not continue with the study.

Heart rate, respiratory rate, $\mathrm{SpO}_{2}$, and $\mathrm{P}_{\mathrm{ET}} \mathrm{CO}_{2}$, were recorded $(n=10$ per subject at each condition) and measurements of $\mathrm{P}_{\mathrm{AW}}, \mathrm{P}_{\mathrm{ES}}$, flow were acquired for three consecutive $15 \mathrm{~s}$ intervals $(45 \mathrm{~s})$ following $20 \mathrm{~min}$ of support with the ICU ventilator and each of the subacute ventilators. Infants who were able to complete the study were first placed onto the ICU ventilator and later transitioned to the subacute ventilator that consistently resulted in the best empirical evidence for subject comfort, gas exchange, and the lowest work of breathing (WOB).

Esophageal pressure changes $\left(\Delta \mathrm{P}_{\mathrm{ES}}\right)$ were used to approximate changes between baseline and maximal deflections in $\mathrm{P}_{\mathrm{ES}}$ and measure respiratory rate during spontaneous breathing efforts. The $\Delta \mathrm{P}_{\mathrm{ES}}$ was also used in the calculations for pressure rate product (PRP). PRP is the product of $\triangle \mathrm{P}_{\mathrm{ES}}$ and respiratory rate $(\mathrm{RR})$ and is used as an index of inspiratory WOB, where:

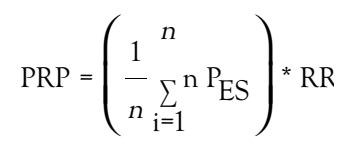


This method of calculation has been described elsewhere in detail [9, 10]. Briefly, PRP provides a more objective measure of effort of breathing than clinical respiratory scores, and it has been shown in children to be more effective in characterizing increasing inspiratory load when compared with phase angle, especially when significant airway resistance is present [10-12]. PRP may be a more useful measure of the amount of energy required to breathe spontaneously during mechanical ventilation than traditional work of breathing measurements because it incorporates respiratory frequency. Also, PRP reflects the magnitude of the entire esophageal pressure swing independent of whether a breath was triggered, whereas standard WOB measurements only assess the integral of airway minus esophageal pressure and volume.

Subject-ventilator asynchrony and increased WOB may result from delays in the time from when the subject initiates a breath (deflection from baseline $\mathrm{P}_{E S}$ ) to the time that peak inspiratory flow is obtained. In this study, we determined that response time is a function of the flow triggering algorithm and responsiveness of the ventilator's demand flow system. We calculated response time from the $\mathrm{P}_{E S}$ measurement at the time that a subject generated a negative deflection in esophageal pressure to the time that peak inspiratory flow was achieved

$$
\text { Response Time }=t(\mathrm{PIF})-t\left(\mathrm{P}_{\mathrm{ES}} \text { breath initiation }\right)
$$

Based on the $\mathrm{P}_{E S}$ measurements, we compared the total number of subject-initiated respiratory efforts to the total number of corresponding breaths triggered on the ventilator where

$$
\text { Subject triggered breaths }(\%)=\frac{\text { triggered ventilator breaths }}{\text { total subject initiated efforts }}
$$

Statistical analyses

Median values and interquartile range (IQR) for $\mathrm{HR}, \mathrm{RR}, \mathrm{SpO}_{2}, \mathrm{ETCO}_{2}$, $\Delta \mathrm{P}_{\mathrm{ES}}$, response times, subject triggered breaths, and PRPs were calculated for each individual subject and subacute ventilator. A Wilcoxon signed rank test was used to compare differences in dependent variables between the two subacute ventilators. Statistical significance was determined a priori for all comparisons as $P<0.05$. While this study was not designed to compare statistical differences between the subacute ventilators with the ICU ventilators, we included these data as baseline measurements on the ICU ventilator prior to placement on the subacute ventilators.

\section{RESULTS}

Between 2012 and 2014 we enrolled eight prematurely born infants with severe $\mathrm{BPD}$, all of which were receiving mechanical ventilation via cuffed tracheostomy tubes. Two infants developed excessive WOB, inability to trigger breaths, and $\mathrm{SpO}_{2}$ levels $<85 \%$ within 5 min of being placed on the LTV 1200 necessitating transfer back to the ICU ventilator, and they were excluded from final analysis because of incomplete data.
Six infants completed the study (Table 1). The mean (SD) weight of the six infants was $4.98(0.56) \mathrm{kg}$. There were no differences between the LTV 1200 and Trilogy 202 in $\mathrm{HR}$ and $\mathrm{SpO}_{2}$ (Table 2). When on the Trilogy 202 infants had lower $\mathrm{P}_{\mathrm{ET}} \mathrm{CO}_{2}, \Delta \mathrm{P}_{\mathrm{ES}}$, respiratory rate (Table 2), PRP (Figure 1), and response times (Figure 2) and greater percent subject triggered breaths (Figure 3$)$ than $\mathrm{w}^{\mathrm{t}} \mathrm{h}$ the LTV $1200(P<0.05)$. All six infants transitioned successfully from the ICU ventilator to the Trilogy 202 on a long-term basis.

\section{DISCUSSION}

The major finding from this study is that the Trilogy 202 ventilator provided short-term ventilator support that was superior to the LTV-1200 with respect to subject-ventilator response time, triggering, and work of breathing in 6 infants with severe BPD requiring long-term mechanical ventilation via tracheostomy tubes. This study was not designed to compare physiologic outcomes between ICU ventilators and subacute ventilators. We used two different ICU ventilators, so we were not able to make any statistical inferences about performance between the subacute ventilators and ICU ventilators. However, it is important to note that all of the physiologic measurements were similar between the Trilogy and ICU ventilators.

Our findings concur with those obtained by Blakeman et al. [13] who observed shorter ventilator response times with the Trilogy 202 than with the LTV-1200 across a range of simulated spontaneous breathing models with simulated airway leaks. The rise time settings could have an impact on response time but they were typically 1 with the Trilogy and 1-2 with the LTV 1200 to promote rapid filling without overshooting/ undershooting the PIPs between the two ventilators. We propose that the observed difference in ventilator response times can be attributed to differences in the triggering algorithms, flow sensor performance, and responsiveness of the gas delivery systems between the two ventilators. Although we did not measure the different circuit volumes, bias flows,

\section{TABLE 2}

\begin{tabular}{|c|c|c|c|c|}
\hline \multirow[b]{2}{*}{ Parameter* } & $\begin{array}{c}\text { ICU } \\
\text { ventilator }\end{array}$ & \multicolumn{3}{|c|}{ Subacute ventilators } \\
\hline & VN500* & LTV $1200^{*}$ & Trilogy $202^{*}$ & $P^{\dagger}$ \\
\hline Heart rate (beats/min) & $158(9)$ & $156(20)$ & $156(26)$ & 0.51 \\
\hline $\mathrm{SpO}_{2}(\%)$ & $99(9)$ & $95(11)$ & $94(9)$ & 0.97 \\
\hline $\mathrm{ETCO}_{2}(\mathrm{~mm} \mathrm{Hg})$ & $44(2)$ & 49 (11) & $45(9)$ & 0.02 \\
\hline $\begin{array}{l}\text { Respiratory rate } \\
\text { (breaths/min) }\end{array}$ & $49(34)$ & $65(21)$ & $49(41)$ & 0.002 \\
\hline$\Delta \mathrm{P}$-esophageal & $4(6)$ & $10(13)$ & $3(5)$ & 0.007 \\
\hline
\end{tabular}

$\begin{aligned} & \text { Respiratory parameters on the ICU and subacute } \\ & \text { ventilators }\end{aligned}$
.

*Values are expressed as median (interquartile range).

${ }^{\dagger} P$ values pertain to differences in values between the two subacute ventilators; Wilcoxon signed rank test used.

\section{TABLE 1}

\begin{tabular}{|c|c|c|c|c|c|}
\hline $\begin{array}{l}\text { Gestational } \\
\text { age (wks) }\end{array}$ & $\begin{array}{l}\text { Chronologic } \\
\text { Age (mos) }\end{array}$ & Weight (kg) & Sex & Diagnoses & $\begin{array}{c}\text { Ventilator settings* } \\
\text { SIMV PIP/PEEP/PS/Rate/FIO }\end{array}$ \\
\hline $24-0 / 7$ & 6 & 5.2 & $\mathrm{M}$ & BPD, pulmonary atresia, tracheomalacia, bronchial stenosis & $32 / 10 / 20 / 30 / 0.35$ \\
\hline $26-1 / 7$ & 5 & 5.7 & M & BPD, tracheomalacia, pulmonary hypertension & $27 / 9 / 12 / 30 / 0.45$ \\
\hline $27-2 / 7$ & 5.5 & 3.9 & $\mathrm{~F}$ & BPD, tracheo/bronchomalacia, necrotizing enterocolitis & $28 / 10 / 18 / 25 / 0.25$ \\
\hline $30-1 / 7$ & 3 & 5.4 & M & BPD; complete tracheal rings, bronchial stenosis & 20/10/10/15/0.21 \\
\hline $25-4 / 7$ & 5 & 4.8 & $\mathrm{~F}$ & BPD, tracheomalacia & $28 / 12 / 16 / 20 / 0.35$ \\
\hline $24-3 / 7$ & 5.5 & 4.9 & $M$ & BPD, tracheomalacia, NEC & $30 / 10 / 22 / 30 / 0.35$ \\
\hline
\end{tabular}

Patient characteristics and ventilator settings

*All ventilators were in the pressure control SIMV/pressure support mode. Inspiratory times ranged from 0.35 to 0.5 seconds.

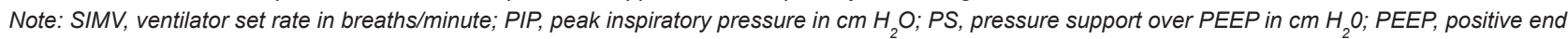
expired pressure in $\mathrm{Cm} \mathrm{H}_{2} \mathrm{O}, \mathrm{FIO}_{2}$, fraction of inspired oxygen; BPD, bronchopulmonary dysplasia. 


\section{FIGURE 1}

Pressure rate product. $X$-axis represents the energy required for subjects to breathe on each of the subacute ventilators. ICU ventilator data shown for graphical comparison of baseline measurements prior to being placed on the subacute ventilators but no statistical comparison was performed. Comparison between subacute ventilators performed using Wilcoxon signed rank test; ${ }^{*} \boldsymbol{P}<0.05$.

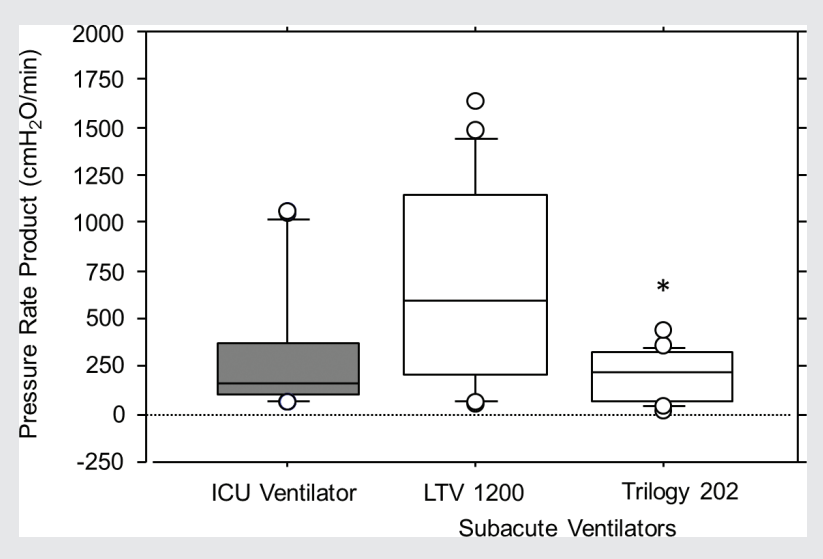

\section{FIGURE 2}

Response time. $\mathrm{X}$-axis represents the response time between the initial subject effort and the peak inspiratory flow delivered by the subacute ventilators. ICU ventilator data shown for graphical comparison of baseline measurements prior to being placed on the subacute ventilators but no statistical comparison was performed. Comparison between subacute ventilators performed using Wilcoxon signed rank test; ${ }^{*} P<0.05$.

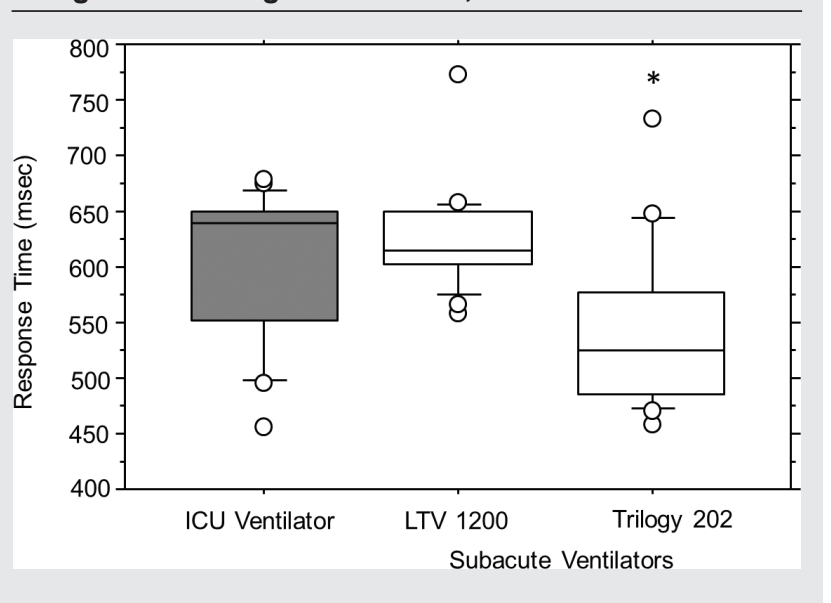

or compliance and resistance between the different circuits used with Trilogy and LTV 1200 ventilators, the proportionally lower circuit volume of the Trilogy single circuit, coupled with higher bias flows, may help to explain the lower observed response times and PRP values.

We were not able to quantify tracheostomy tube leaks, but several of the subjects enrolled in this study had small audible airway leaks, despite using cuffed tubes. The Trilogy 202 uses an adaptive triggering algorithm that modifies triggering and cycling characteristics in the presence of dynamic air leaks, whereas the LTV-1200 employs triggering compensation based on preset parameters and will only adjust for leaks up to $6 \mathrm{~L} / \mathrm{min}$ and only if

\section{FIGURE 3}

Percentage of subject triggered breaths. X-axis represents the proportion of subject-initiated respiratory efforts to the total number of corresponding breaths triggered on the ventilator. ICU ventilator data shown for graphical comparison of baseline measurements prior to being placed on the subacute ventilators but no statistical comparison was performed. Comparison between subacute ventilators performed using Wilcoxon signed rank test; ${ }^{*} P<0.05$

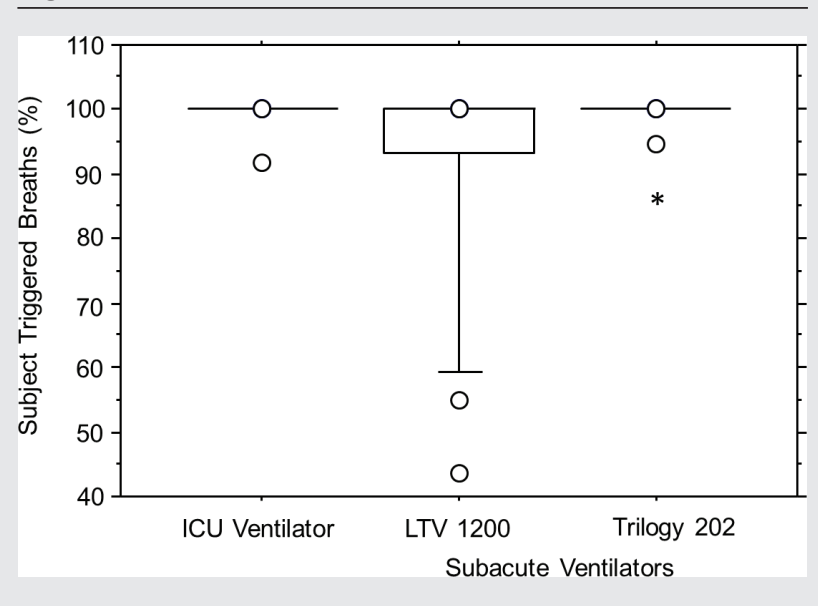

there is a stable detectable leak during exhalation. The effort required to trigger breaths in the face of small tracheostomy tube leaks may have also contributed to lower PRPs and response times in this study.

Another possible reason for the difference in PRP, ventilator response times, and triggering may be related to where the triggering mechanisms are actually located within the ventilator circuit. The Trilogy 202 allows subject triggering with a mass flow sensor inside the ventilator through a passive, single-limb circuit, whereas the LTV 1200 senses subject effort using an integrated differential pressure pneumotachometer situated proximal to the subject airway with a dual-limb subject circuit. In chronically ventilated subjects there may be a disadvantage with a proximal flow sensor because the sensor accuracy may be more easily affected by humidity, temperature, secretions, and fluid condensate compared to a sensor that is housed within the ventilator. Also, flow sensors situated at the airway may increase mechanical deadspace and resistance, which may increase the energy required by a subject to breath on the LTV 1200. Of note, with the Trilogy 202, despite its better performance, we found the median ventilator response time was still $>600 \mathrm{msec}$, which is higher than that reported by both Blokpoel et al. [14] and Blakeman et al. [13]. Both of those investigators used airway pressure and flow characteristics to determine onset of respiration in a mechanical lung model. The longer ventilator response time observed in our study was likely due to the use of esophageal manometry to define the onset of subject effort and also differences in airway obstruction in our subject population compared with the pediatric lung model used in those in-vitro studies. Also, unlike previous methods that identified ventilator response times as the time it takes a subject to initiate a breath to the time it takes for the onset of a mechanical breath to be sensed at the airway, we felt that peak inspiratory flow would be more descriptive from a performance standpoint because it takes into account the time between subject effort, breath onset, and time to reach the maximal flow delivered to the subject. Further subacute ventilator improvements are needed to reduce ventilator response times and triggering as these are a primary contributor to ventilator asynchrony [15], and ventilator asynchrony is associated with negative outcomes, to include prolonged intubation [16, 17], increased sedative use [18-20], and higher mortality [21]. 
Our subjects with BPD likely had air trapping and intrinsic PEEP [22] that had to be overcome with generating sufficient pleural pressure before a change in circuit pressure and flow could allow ventilator triggering to occur [23]. We showed statistically significant differences in the number of spontaneously triggered breaths between the two subacute ventilators. One of the subjects was only able to trigger the LTV 1200 ventilator $56 \%$ of the time but was able to trigger the Trilogy $100 \%$ of the time. It is unclear whether the subject had a significant trache tube leak or whether they had greater difficulty initiating breaths with the LTV 1200 due to a more severe form of BPD (high intrinsic PEEP) or because the subject was extremely small $(3.9 \mathrm{~kg})$ compared with the other subjects included in this study. Nonetheless, the infant was clinically stable with $\mathrm{SpO}_{2} \sim 88 \%$ and didn't appear to have any significant distress. Two infants were excluded from the original eight eligible patients in the study (insufficient data to be shown) and returned to the ICU ventilator because they were unable to trigger breaths from the LTV 1200 ventilator. As such, this study was designed only to include clinically stable infants that could trigger the respective ventilators for the majority of the time.

The calculation of subject-triggered breaths provides information about the relative proportion of subject-triggered mechanical breaths delivered by the ventilator but it doesn't take into account the energy expenditure required by the subject to trigger those breaths. The PRP reflects those initial efforts as well as all maximal efforts required by the subject throughout the entire inspiratory effort. As such, we postulate that the significant reductions in PRP observed in subjects supported by the Trilogy 202 may be due, in part, to the lower pleural pressures required to effectively trigger this ventilator.

In our study we noted improvement ineffort of breathing, PRP, and triggering with the Trilogy 202 ventilator compared with the LTV 1200. As mentioned previously, we speculate that these differences are related to the force necessary to trigger a breath and receive appropriate flow from within the ventilator system. The PRP has been used for respiratory disease severity stratification in children with upper airway obstruction [24] and also in rhesus monkeys with simulated upper airway obstruction [12]; it is a clinically relevant measure of inspiratory load. Excessive inspiratory loads during ventilation may be a contributor to diaphragm dysfunction [25] and may have clinical relevance in regards to pulmonary rehabilitation. As mentioned previously, we did not observe clinically important differences in $\mathrm{SpO}_{2}, \mathrm{HR}$, and $\mathrm{ETCO}_{2}$ between the Trilogy and LTV despite differences in work of breathing as assessed by the PRP. Our findings are similar to Ross et al. [12] who observed stepwise rises in PRP as increasingly high inspiratory resistors were added to both intubated and spontaneously breathing rhesus monkeys; there were no significant changes in clinical parameters $\left(\mathrm{SpO}_{2}, \mathrm{HR}, \mathrm{ETCO}_{2}\right)$ until the highest resistors were added and the monkeys were unable to match the inspiratory load.

There are several limitations to our short-term physiologic study. We only evaluated six infants with a single disease (BPD) process and from a single institution. Transitioning large numbers of infants to subacute ventilators is a rare occurrence at our institution. As such, acquiring data in a large number of subjects would take decades with ventilator technology changes making those efforts a moot point. Other investigators have also found differences in patient-ventilator synchrony in using a relatively small numbers of neonatal subjects [26]. Our findings are limited to subjects with BPD, so it is unclear whether there would be different outcomes in subjects with other forms of chronic respiratory illness supported by the different ventilators. It is important to note that all subjects in this study had at least one form of significant upper airway obstructive lesion (e.g., tracheomalacia) and another had Necrotizing enterocolitis that was treated surgically. It is unclear how these factors may have contributed to these findings or whether infants experiencing BPD would have different short-term outcomes in the absence of these complications. Also, this was a study of short duration (20 min at each condition); therefore, it is difficult to extrapolate these results to longer time periods. We only used two subacute ventilators, all in a single mode of ventilation (PC SIMV with PS). Lastly, we evaluated performance in patients that were $<5 \mathrm{~kg}$ and these subacute ventilators are approved for use in patients $>5 \mathrm{~kg}$. As such, these findings should be approached with trepidation, as larger infants may be able to be supported similarly using either of the subacute ventilators mentioned in this study and conversely, smaller spontaneously breathing infants may not be able to be supported with these ventilators.

\section{CONCLUSION}

In this small group of infants with ventilator-dependent BPD we found that the Trilogy 202 ventilator performed better than the LTV 1200 with respect to response time, respiratory rate, triggering, and WOB (PRP). We postulate that this was because of, in part, the Trilogy 202's adaptive triggering algorithm and responsive gas delivery system, and location of the flow sensor. These pilot data may be useful for informing future clinical study design and understanding differences in the level of support provided by different subacute ventilators in infants with BPD. Future studies will be needed to determine whether these new ventilator technologies play a role in reducing length of ICU stay.

\section{CONFLICT OF INTEREST}

Robert DiBlasi has served as a consultant, received research funding, and has been on the speaker's bureau for Draeger Medical and Mallinckrodt Medical. He also currently has a grant from Aerogen Pharma (\#15915). The other authors have no conflicts of interest to disclose. We received no funding support for this study.

\section{REFERENCES}

1. US Congress OTA. Technology dependent children: Hospital vs. home care. Vol NTIS order \#PB87-194551. Office Technology Assessment Archive: Federation of American Scientists. Washington, DC: US Government Printing Office; 1987.

2. Gowans M, Keenan HT, Bratton SL. The population prevalence of children receiving invasive home ventilation in Utah. Pediatr Pulmonol 2007;42(3): 231-6. doi: 10.1002/ppul.20558.

3. Graham RJ, Fleegler EW, Robinson WM. Chronic ventilator need in the community: A 2005 pediatric census of Massachusetts. Pediatrics 2007;119(6): e1280-7

4. Benneyworth BD, Gebremariam A, Clark SJ, Shanley TP, Davis MM. Insubject health care utilization for children dependent on long term mechanical ventilation. Pediatrics 2011;127(6): e1533-41. doi: 10.1542/ peds.2010-2026

5. Cristea AI, Carroll AE, Davis SD, Swigonski NL, Ackerman VL. Outcomes of children with severe bronchopulmonary dysplasia who were ventilator dependent at home. Pediatrics 2013;132(3): 727-34. doi: 10.1542/peds.2012-2990.

6. Richard JC, Carlucci A, Breton L, et al. Bench testing of pressure support ventilation with three different generations of ventilators. Intensive Care Med 2002;28(5): 1049-57. doi: 10.1007/s00134-002-1311-9.

7. Baraldi E, Filippone M. Chronic lung disease after premature birth. N Engl J Med 2007;357(19): 1946-55

8. Baydur A, Behrakis PK, Zin WA, Jaeger M, Milic-Emili J. A simple method for assessing the validity of the esophageal balloon technique. Am Rev Respir Dis 1982;126: 788-91

9. Klein M, Reynolds LG. Relief of sleep-related oropharyngeal airway obstruction by continuous insufflation of the pharynx. Lancet 1986; 1(8487): 935-9. doi: 10.1016/S0140-6736(86)91043-3.

10. Graham AS, Chandrashekharaiah G, Citak A, Wetzel RC, Newth CJ, Positive end-expiratory pressure and pressure support in peripheral airways obstruction: Work of breathing in intubated children. Intensive Care Med 2007;33(1): 120-7. doi: 10.1007/s00134-006-0445-6.

11. Willis BC, Graham AS, Yoon E, et al. Pressure-rate products and phase angles in children on minimal support ventilation and after extubation. Intensive Care Med 2005;31: 1700-5. doi: 10.1007/s00134-005-2821-z.

12. Ross PA, Hammer J, Khemani R, Klein M, Newth CJ, Pressure-rate product and phase angle as measures of acute inspiratory upper airway obstruction in rhesus monkeys. Pediatr Pulmonol 2010;45(7): 639-44. doi: $10.1002 /$ ppul.21212.

13. Blakeman TC, Rodriquez D, Hanseman D, Branson RD, Bench evaluation of 7 home-care ventilators. Respir Care 2011;56(11): 1791-8. doi: 10.4187 /respcare. 01176 . 
14. Blokpoel RGT, Burgerhof JGM, Markhorst DG, Kneyber MCJ, Subject-ventilator asynchrony during assisted ventilation in children. Pediatr Crit Care Med 2016;17(5): 204-11. doi: 10.1097/PCC.0000 000000000669.

15. Kondili E, Prinianakis G, Georgopoulos D, Patient-ventilator interaction. Br J Anaesth 2003;91(1): 106-19. doi: 10.1093/bja/aeg129.

16. Thille AW, Rodriguez P, Cabello B, Lellouche F, Brochard L, Subjectventilator asynchrony during assisted mechanical ventilation. Intensive Care Med 2006;32(10): 1515-22. doi: 10.1007/s00134-006-0301-8.

17. De Wit M, Miller KB, Green DA, Ostman HE, Gennings C, Epstein SK, Ineffective triggering predicts increased duration of mechanical ventilation. Crit Care Med 2009;37(10): 2740-5

18. Hansen-Flaschen JH, Brazinsky S, Basile C, Lanken PN, Use of sedating drugs and neuromuscular blocking agents in subjects requiring mechanical ventilation for respiratory failure. A national survey. JAMA 1991;266: 2870-5. doi: 10.1001/jama.1991.03470200082040.

19. De Wit M, Pedram S, Best AM, Epstein SK, Observational study of subject-ventilator asynchrony and relationship to sedation level. J Crit Care 2009;24(1): 74-80. doi: 10.1016/j.jcrc.2008.08.011.

20. Shehabi Y, Chan L, Kadiman S, et al. Sedation depth and long-term mortality in mechanically ventilated critically ill adults: A prospective longitudinal multicenter cohort study. Intensive Care Med 2013;39(5): 910-18. doi: 10.1007/s00134-013-2830-2.

21. Blanch L, Villagra A, Sales B, et al. Asynchronies during mechanical ventilation are associated with mortality. Intensive Care Med 2015;41(4): 633-41. doi: 10.1007/s00134-015-3692-6.

22. Robin B, Kim Y-J, Huth J, et al. Pulmonary function in bronchopulmonary dysplasia. Pediatr Pulmonol 2004;37(3): 236-42. doi: 10.1002/ ppul.10424.22.

23. MacIntyre NR, Cheng KCG, McConnell R, Applied PEEP during pressure support reduces the inspiratory threshold load of intrinsic PEEP. Chest 1997;111(1): 188-93. doi: 10.1378/chest.111.1.188.

24. Khemani RG, Hotz J, Morzov R, et al. Evaluating risk factors for pediatric post-extubation upper airway obstruction using a physiology-based tool. Am J Respir Crit Care Med 2016;193(2): 198-209. doi: 10.1164/ rccm.201506-1064OC.

25. Goligher EC, Fan E, Herridge MS, et al. Evolution of diaphragm thickness during mechanical ventilation: Impact of inspiratory effort. Am J Respir Crit Care Med 2015;192(9): 1080-8. doi: 10.1164/rccm.201503-06200C.

26. Wood SM, Thurman TL, Holt SJ, Bai S, Heulitt MJ, Courtney SE. Effect of ventilator mode on patient-ventilator synchrony and work of breathing in neonatal pigs. Pediatr Pulmonol 2017;9999: 1-7. doi: 10.1002/ppul.23682. 